\title{
ESTUDOS SOBRE AS TÁTICAS E AS ESTRATÉGIAS REPRODUTIVAS DE SETE ESPÉCIES DE PEIXES DE ÁGUA DOCE DO RIO GRANDE DE NORTE, BRASIL
}

\author{
N. H. C. BARROS ${ }^{1 *}$, L. T. B. LIMA ${ }^{1}$, A. S. ARAÚJO ${ }^{2}$, L. L. GURGEL ${ }^{3}$, N.T. CHELLAPPA ${ }^{1}$ e S. CHELLAPPA ${ }^{1}$ \\ ${ }^{1}$ Universidade Federal do Rio Grande do Norte (UFRN) \\ ${ }^{2}$ Universidade Federal do Amapá (UNIFAP) \\ ${ }^{3}$ Instituto Federal de Educação, Ciência e Tecnologia do Rio Grande do Norte, Campus Natal Zona Norte \\ nirleyhirachy@hotmail.com*
}

Artigo submetido em novembro/2015 e aceito em abril/2016

DOI: $10.15628 /$ holos.2016.3648

\section{RESUMO}

O presente trabalho verificou as táticas e estratégias reprodutivas de sete espécies de peixes de água doce do Estado do Rio Grande do Norte, Brasil. Para peixes de água doce, três padrões de estratégias reprodutivas foram propostas: (1) estrategistas de equilibrio (K), que são peixes de tamanho corporal grande, primeira maturação tardia, desovas repetidas, com longo período de vida e cuidado parental; (2) estrategistas sazonais, são peixes de tamanho corporal intermediário a grande, fecundidade intermediária a alta e sem cuidado parental; (3) estrategistas oportunistas ( $r$ ), são peixes de pequeno tamanho corporal com primeira maturação precoce, período de vida curto, desovas repetidos e com pouco ou nenhum cuidado parental. Os aspectos reprodutivos das espécies: cará, Cichlasoma orientale (Kullander, 1983), niquim, Pimelodella gracilis (Valenciennes, 1835), curimatã, Prochilodus brevis (Steindachner, 1875), jacundá,
Crenicichla menezesi (Ploeg, 1991), mussum, Synbranchus marmoratus (Bloch , 1795), sardinha de água doce, Triportheus angulatus (Spix \& Agassiz, 1829) e cascudo, Hypostomus pusarum (Starks, 1913) foram verificados considerando-se o tamanho do corpo, proporção sexual, tipo de crescimento, comprimento de primeira maturação sexual, aspectos do desenvolvimento das gônadas, fator de condicão, fecundidade e tipo de desova. Os resultados indicam que as espécies $C$. orientale e $S$. marmoratus podem ser considerados como estrategistas de equilibrio $K$, enquanto $C$. menezesi, $P$. brevis e $H$. pusarum podem ser considerados como estrategistas sazonais. A espécies $P$. gracilis e $T$. angulatus podem ser considerados como estrategista $r$. O presente estudo fornece informações sobre os aspectos reprodutivos dos peixes neotropicais de água doce do Rio Grande do Norte, Brasil.

PALAVRAS-CHAVE: Reprodução dos peixes, estratégias reprodutivas, peixes de água doce do Rio Grande do Norte, aspectos reprodutivos.

\section{STUDIES ON REPRODUCTIVE TACTICS AND STRATEGIES OF SEVEN FRESHWATER FISH SPECIES FROM RIO GRANDE DO NORTE, BRAZIL}

\begin{abstract}
This work determined the reproductive tactics and strategies of seven freshwater fish species of Rio Grande do Norte, Brazil. Life history traits of freshwater fish suggest three reproductive strategies: (1) Equilibrium strategists (K) involving large fish with delayed first sexual maturity and long life); (2) seasonal strategists, fish with médium sized body, médium fecundity and without parental care; (3) oportunistic strategists $(r)$, involving fish with small sized body, early sexual maturity and short life span. The present study verified the body size, sex ratio, type of growth, length at first sexual maturity, aspects of gonad development, condition factor, fecundity and type of spawning of Cichlasoma orientale
\end{abstract}

KEYWORDS: Fish reproduction, reproductive strategies, freshwater fish of Rio Grande do Norte, reproductive aspects.
(Kullander, 1983), Crenicichla menezesi (Ploeg, 1991); graceful pimelodella, Pimelodella gracilis (Valenciennes, 1835), Brazilian bocachico, Prochilodus brevis (Steindachner, 1875), the marbled swamp eel, Synbranchus marmoratus (Bloch, 1795), the freshwater sardine Triportheus angulatus (Spix \& Agassiz, 1829) and armoured catfish, Hypostomus pusarum (Starks, 1913). The results suggest that the species C. orientale and $S$. marmoratus could be considered as equilibrium strategists $(K)$, while $C$. menezesi, $P$. brevis and $H$. pusarum could be considered as seasonal estrategistas. $P$. gracilis and $T$. angulatus could be considered as oportunistic strategists (r). This study provides information on reproductive aspects of neotropical freshwater fish of Rio Grande do Norte, Brazil. 


\section{INTRODUÇÃO}

"As bacias hidrográficas sob o domínio do semiárido apresentam características peculiares, como regime intermitente e sazonal de seus rios, reflexo direto das precipitações escassas e irregulares, associadas à alta taxa de evaporação hídrica"'(NASCIMENTO, 2010, p.1). Esssas condições climáticas exercem importante papel na organização e funcionalidade dos ecossistemas aquáticos, onde as espécies presentes desenvolvem diversas adaptações para a sobrevivência, que acarretam em competições intra e interespecíficas, alterações na estrutura das comunidades, disponibilidade de recursos naturais e estratégias reprodutivas (LUNDBERG et al., 1998; MENESCAL, 2002; ROSA et al., 2004 e 2005; CHELLAPPA et al., 2009).

A ictiofauna das bacias hidrográficas do semiárido representa o resultado de processos ecológicos que determinaram as adaptações das espécies às condições climáticas e o regime hidrológico da região. "A compilação taxonômica dos peixes que ocorrem no bioma Caatinga revelou a presença de 240 espécies distribuídas em sete ordens"'(BARROS, 2012, p.5). No Rio Grande do Norte, foram realizados vários estudos em relação aos aspectos reprodutivos das espécies de peixes de água doce (Tabela 1). Essas pesquisas têm servido de parâmetros para o entendimento dos mecanismos que envolvem a perpetuação, manejo e exploração racional das espécies de peixes de água doce do Estado.

A estratégia reprodutiva pode ser definida como um conjunto de características que uma espécie deverá manifestar para ter sucesso na reprodução, de modo a garantir o equilíbrio populacional. Para peixes de água doce, três padrões de estratégias reprodutivas são propostas: (1) estrategistas de equilibrio (K), que são peixes de tamanho corporal grande, primeira maturação tardia, desovas repetidas, com longo período de vida e cuidado parental; (2) estrategistas sazonais, são peixes de tamanho corporal intermediário a grande, fecundidade intermediária a alta e sem cuidado parental; (3) estrategistas oportunistas ( $r$ ), são peixes de pequeno tamanho corporal com primeira maturação precoce, período de vida curto, desovas repetidos e com pouco ou nenhum cuidado parental (WINEMILLER \& ROSE, 1992; KING \& MCFARLANE, 2003; CHELLAPPA et al., 2013).

"As estratégias reprodutivas dos peixes englobam táticas extremas, que permitiram sua adaptação a ambientes nos quais tanto as condições bióticas, como disponibilidade de alimento e pressão de predação, quanto às abióticas, como temperatura, regime de chuvas, fotoperíodo, oxigênio disponível, dentre outras, variam amplamente no espaço e no tempo"(ARAÚJO, 2012, p.16).

As principais táticas que compõem a estratégia reprodutiva de peixes são: tamanho corporal, a relação peso-comprimento, proporção sexual, o tamanho da primeira maturação sexual, o desenvolvimento das gônadas, a fecundidade, índice gonadosomático (IGS), tipo e época de desova (CHELLAPPA et al., 2009; CHELLAPPA et al., 2013). Estudos sobre estratégias reprodutivas são de grande interesse, pois além da melhor compreensão da história de vida de diferentes organismos podem conduzir a implicações evolutivas permitindo discussões sobre os processos reprodutiva ocorridos no passado, que provocaram, em última instância, a especiação ictiológica. Estudos sobre a reprodução dos peixes de água doce do Rio Grande do Norte é considerada necessária.

Diante disto, o presente trabalho apresenta as táticas e estratégias reprodutivas de sete espécies de peixes de água doce do Estado do Rio Grande do Norte: cará, Cichlasoma orientale 
(Kullander, 1983), niquim, Pimelodella gracilis (Valenciennes, 1835), curimatã, Prochilodus brevis (Steindachner,1875), jacundá, Crenicichla menezesi (Ploeg, 1991), mussum, Synbranchus marmoratus (Bloch , 1795), sardinha de água doce, Triportheus angulatus (Spix \& Agassiz, 1829) e cascudo, Hypostomus pusarum (Starks, 1913). As táticas reprodutivas foram investigadas a fim de determinar suas estratégias reprodutivas.

\section{METODOLOGIA}

\subsection{Local de estudo}

A bacia hidrográfica de Piranhas-Assu, RN (Figura 1) está localizada entre $04^{\circ}$ e $08^{\circ}$ de Latitude $\mathrm{S}$ e entre $36^{\circ}$ e $39^{\circ}$ de Longitude $\mathrm{W}$, e está totalmente inserida na região do semiárido, abrangendo um território de 44.000 km² distribuído entre os Estados da Paraíba e Rio Grande do Norte (CBH, 2014).

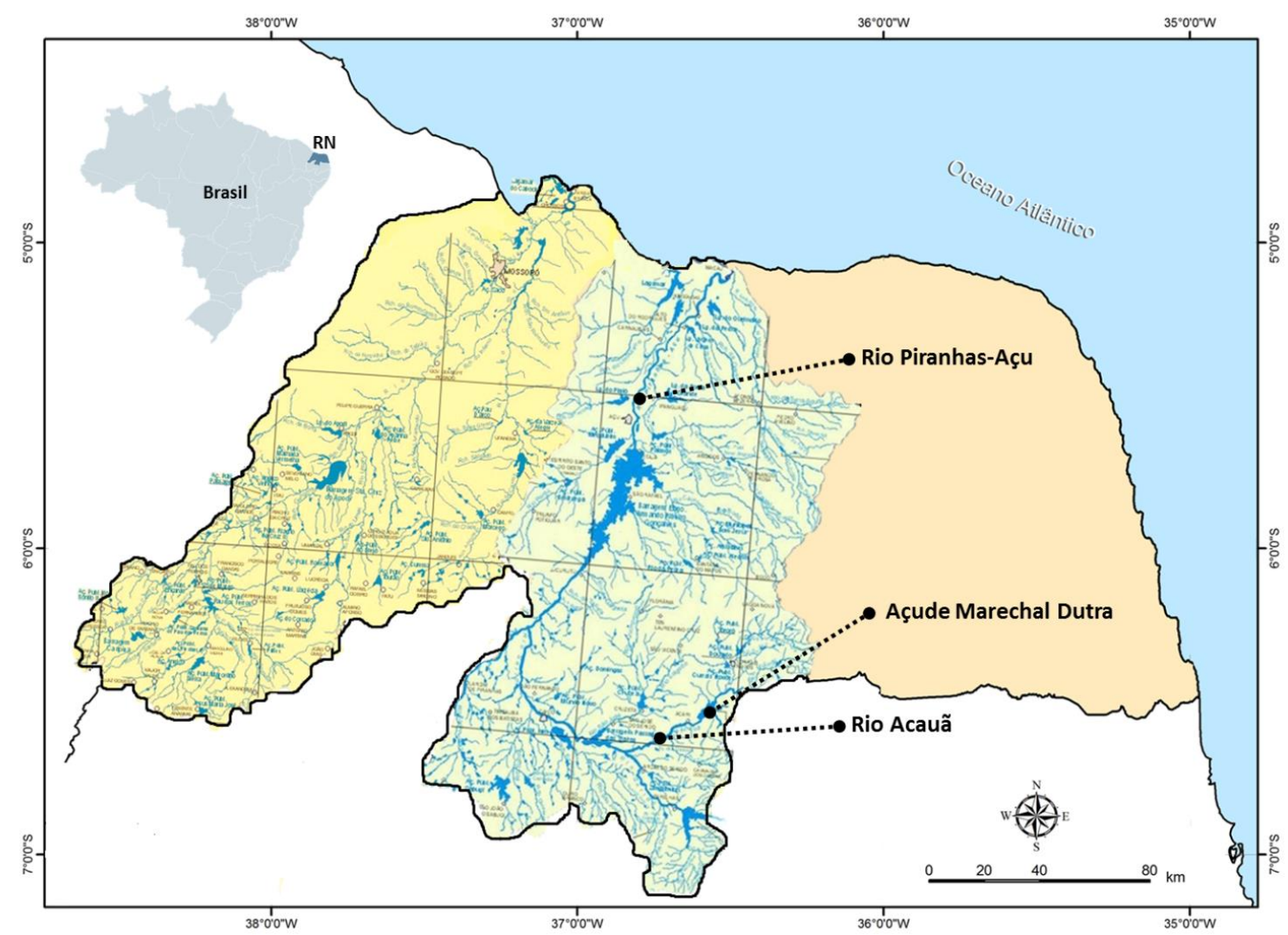

Figura 1: Área de estudo: Bacia hidrográfica do rio Piranhas-Assu, localizada entre $04^{\circ}$ e $08^{\circ}$ de Latitude $S$ e entre $36^{\circ}$ e $39^{\circ}$ de Longitude W, Rio Grande do Norte, Brasil (Fonte: IDEC, 1978).

\subsection{Espécies em estudo}

Os exemplares dos peixes cará, $C$. orientale; niquim, $P$. gracilis; curimatã, $P$. brevis; jacundá, C. menezesi; mussum, S. marmoratus; sardinha de água doce; T. angulatus e cascudo, H. pusarum, foram capturados na bacia hidrográfica de Piranhas-Assu, RN (Figura 2). Foram verificadas suas táticas reprodutivas, tais como, amplitude de comprimento total e o peso total, a relação peso- 
comprimento, tipo de crescimento, proporção sexual, primeira maturação sexual, desenvolvimento das gônadas, fecundidade, tipo de desova e o período reprodutivo.
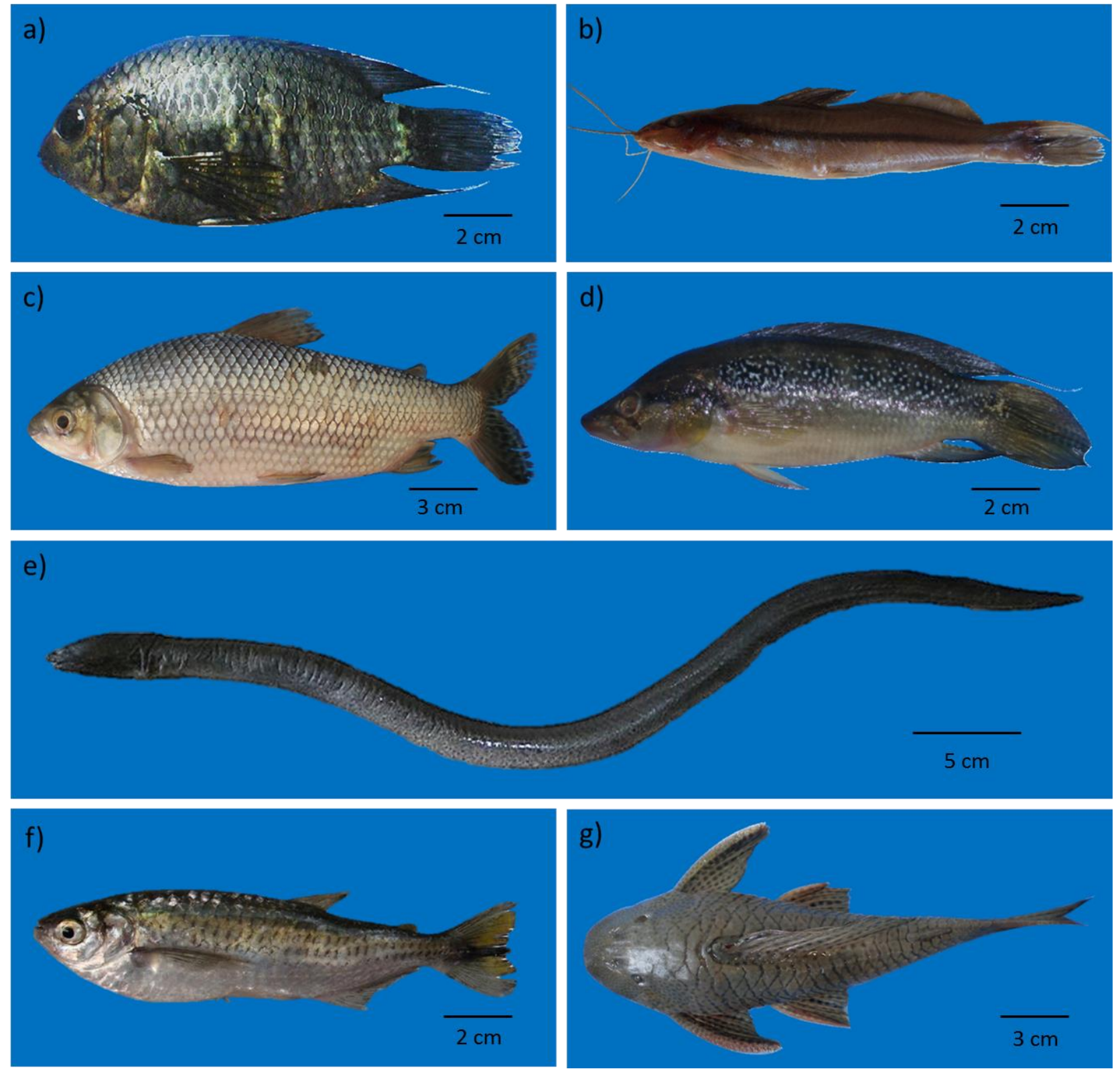

Figura 2: Espécies de estudo capturadas na Bacia hidrográfica do rio Piranhas-Assu, Rio Grande do Norte, Brasil: a) cará, Cichlasoma orientale; b) niquim, Pimelodella gracilis; c) curimatã, Prochilodus brevis; d) jacundá, Crenicichla menezesi; e) mussum, Synbranchus marmoratus; f) sardinha de água doce, Triportheus angulatus e cascudo; g) Hypostomus pusarum.

\subsection{Aspectos reprodutivos}

A relação peso-comprimento das espécies de peixes em consideração foi estabelecida através da equação potencial, $\mathrm{W} t=\phi \mathrm{Ls} \theta$. Os dados de peso $(\mathrm{Wt})$ e comprimento total $(\mathrm{Ls})$ foram usados na equação potencial onde; $\phi$ é o coeficiente fator de condição e $\theta$ é o coeficiente angular ou coeficiente de crescimento, que permite determinar o tipo de crescimento de cada espécie (JOBLING, 2008; FROESE,1998). A proporção sexual foi dada como M:F calculada em relação ao 
número total de machos / número total de fêmeas (VAZZOLLER, 1996). A primeira maturação sexual das espécies $\left(L_{50}\right)$ foi determinada pela distribuição da freqüência relativa de machos e fêmeas adultos em classes de comprimento total (MORENO et al., 2005). Para o cálculo do fator de condição (K) das especies, utilizou-se a expressão: $K=100$ (Wt / Lpb) (FROESE, 2006). Desenvolvimento das gônadas foi realizado através do exame macroscópico para a classificação do desenvolvimento gonadal. Fecundidade absoluta foi avaliada através do número de ovócitos que uma fêmea irá desovar no período reprodutivo. O tipo de desova foi avaliado através da medição do diâmetro dos ovócitos (em $\mu \mathrm{m}$ ) e através da análise histológico do desenvolvimento dos ovócitos. O período reprodutivo foi determinado através da distribuição das frequências relativas (\%) de cada estádio de maturação das gônadas e a variação da média mensal do índice gonadossomático (IGS), considerando os sexos separados (VAZZOLER, 1996).

\section{RESULTADOS E DISCUSSÃO}

\subsection{Peso e comprimento dos peixes}

Comprimento total e o peso total para sexos agrupados de Cichlasoma orientale (Tabela 1). Foram registrados machos maiores e mais pesados que as fêmeas (Gurgel, 2010; Gurgel et al.,2011;Nascimento et al., 2012b). Quando os machos são de maior tamanho, alguns fatores atuam com maior intensidade na seleção sexual. Em diversas espécies de peixes, machos maiores tendem a vencer encontros agressivos com outros machos, manter territórios de melhor qualidade e obter melhor acesso às fêmeas (CHELAPPA et al., 1999; CACHO et al., 2006; CHELAPPA et al., 2014).

O comprimento total e peso total para fêmeas e machos de Prochilodus brevis (Tabela 1). As fêmeas atingiram valores de comprimento e peso total maiores que os machos (Nascimento, 2006; Gurgel, 2010; Gurgel et al., 2012; Nascimento et al., 2012a; Nascimento et al., 2012b). Resultados semelhantes foram observados em estudos com a espécie Prochilodus scrofa, em viveiros (GODINHO \& RIBEIRO, 1985).

O comprimento total e peso total para fêmeas e machos de Crenicichla menezesi (Tabela 1) Os machos são maiores do que as fêmeas (Araújo, 2012; Araújo et al., 2012; Chellappa et al., 2013; Araújo et al., 2014). Geralmente, macho ciclídeos são maiores e mais pesados do que as fêmeas, como consequência da evolução comportamental em formação de pares e cuidado parental, o que aumenta o sucesso reprodutivo (CACHO et al., 2006; CACHO et al., 2007).

O comprimento total e o peso total para os quatro tipos sexuais (machos primários, fêmeas, intersexos e machos secundários) (Tabela 1). Os machos secundários foram os mais pesados enquanto os machos primários apresentaram os menores pesos. A maior frequência de fêmeas e intersexos esteve na amplitude de classe de $66 \mathrm{~g}$ a $126 \mathrm{~g}$ (Damasceno, 2008; Barros, 2012; Barros et al., 2012; Barros et al., 2013a;Barros et al., 2013b; Chellappa et al., 2013; Barros et al., 2014).

O comprimento total e peso total para fêmeas e machos de Triportheus angulatus (Tabela 1) (Araújo, 2012; Araújo et al., 2012; Nascimento et al., 2012b;Chellappa et al., 2013). Os exemplares de T. angulatus (11 a 17,4 cm) foram relativamente menores do que os exemplares captu- 
rados em Porto Velho, Rondônia $(7$ a 38 cm) (DORIA \& QUEIROZ, 2008) e no Lago Camaleão, Manaus ( 3 a 25,5 cm) (YAMAMOTO et al., 2004) e em lagos da Amazônia Central (7 a 25,5cm) (PRESTES et al., 2010).

O comprimento total e peso total para fêmeas e machos de Hypostomus pusarum (Tabela 1) (Bueno, 2004; Bueno et al., 2008; Pessoa et al., 2013). Resultados semelhantes foram observados em estudos realizados com a mesma espécie, no reservatorio de Santo Anastácio em Fortaleza, Brasil (SÁNCHEZ-BOTERO et al., 2014).

Tabela 1: Amplitude de Comprimento total Lt $(\mathrm{cm})$ e Peso tota Wt $(\mathrm{g})$ de Cichlasoma orientale, Prochilodus brevis, Crenicichla menezesi, Synbranchus marmoratus, Triportheus angulatus e Hypostomus pusarum peixes de água doce do Estado do Rio Grande do Norte.

\begin{tabular}{|c|c|c|}
\hline Espécies & Comprimento total Lt (cm) & Peso total Wt (g) \\
\hline Cichlasoma orientale & $\begin{array}{l}\text { Lt (sexos agrupados): } 1,04 \mathrm{~cm} \text { a } 14,70 \\
\mathrm{~cm}(11,44 \pm 1,14) .\end{array}$ & $\begin{array}{l}\text { Wt (sexos agrupados): } 12,0 \mathrm{~g} \text { a } 90,50 \mathrm{~g} \\
(37,18 \pm 13,69) \text {. }\end{array}$ \\
\hline \multirow{2}{*}{ Prochilodus brevis } & Lt (fêmeas): $23,0 \mathrm{~cm}$ a $30,0 \mathrm{~cm}$ & Wt (fêmeas): 215,6 g a 513,2 g \\
\hline & Lt (machos): $23,5 \mathrm{~cm}$ a $28,0 \mathrm{~cm}$ & Wt (machos): $204,2 \mathrm{~g}$ a $322,4 \mathrm{~g}$ \\
\hline \multirow{2}{*}{ Crenicichla menezesi } & $\begin{array}{l}\text { Lt (fêmeas): } 11,38 \mathrm{~cm} \text { a } 19,5 \mathrm{~cm}(14,8 \\
\mathrm{cm} \pm 2,70) .\end{array}$ & $\begin{array}{l}\text { Wt (fêmeas): } 12,0 \mathrm{~g} \text { a } 90,50 \mathrm{~g}(37,18 \pm \\
13,69) \text {. }\end{array}$ \\
\hline & $\begin{array}{l}\text { Lt (machos): } 12,64 \mathrm{~cm} \text { a } 17,2 \mathrm{~cm}(16,2 \pm \\
2,69) .\end{array}$ & $\begin{array}{l}\text { Wt (machos): } 32,4 \text { g a } 79,22 \text { g }(54,6 \pm \\
13,64) \text {. }\end{array}$ \\
\hline \multirow{3}{*}{ Synbranchus marmoratus } & $\begin{array}{l}\text { Lt (machos primários): } 22 \mathrm{~cm} \text { a } 32 \mathrm{~cm} \\
(26,3 \pm 3,95) \text {; (fêmeas): } 22 \mathrm{~cm} \text { a } 56 \mathrm{~cm}\end{array}$ & $\begin{array}{l}\text { Wt (machos primários): } 6 \text { g a } 50 \text { g }(21,61 \pm \\
\text { 16,94); (fêmeas): } 9 \text { g a } 210 \text { g }(101,4 \pm 44,5) \text {; }\end{array}$ \\
\hline & $(43,9 \pm 6,85)$; (intersexos): 37 a $56(49,3$ & (intersexos): $55 \mathrm{~g}$ a $222 \mathrm{~g}(148,3 \pm 48,3) \mathrm{e}$ \\
\hline & $\begin{array}{l} \pm 6,7) \mathrm{cm} \text { e (machos secundários): } 45 \\
\mathrm{~cm} \text { e } 68 \mathrm{~cm}(57,0 \pm 4,9) .\end{array}$ & $\begin{array}{l}\text { (machos secundários): } 32 \text { g a } 327 \mathrm{~g}(203,0 \pm \\
70,3) .\end{array}$ \\
\hline \multirow{2}{*}{ Triportheus angulatus } & $\begin{array}{l}\text { Lt (fêmeas): } 14,52 \mathrm{~cm} \text { a } 15,9 \mathrm{~cm}(14,10 \\
\pm 3,731) .\end{array}$ & $\begin{array}{l}\text { Wt (fêmeas): } 27,17 \text { g a } 39,66 \text { g }(30,26 \pm \\
10,29) \text {. }\end{array}$ \\
\hline & $\begin{array}{l}\text { Lt (machos): } 12,33 \mathrm{~cm} \text { a } 15,85 \mathrm{~cm} \\
(13,60 \pm 0,409) .\end{array}$ & $\begin{array}{l}\text { Wt (machos): } 28,25 \mathrm{~g} \text { a } 40,62 \mathrm{~g}(32,94 \pm \\
10,93) .\end{array}$ \\
\hline \multirow{2}{*}{ Hypostomus pusarum } & $\begin{array}{l}\text { Lt (fêmeas): } 22.0 \mathrm{~cm} \text { a } 29.0 \mathrm{~cm}(25.8 \pm \\
1.7) .\end{array}$ & $\begin{array}{l}\text { Wt (fêmeas): } 102.0 \text { g a } 290.5 \text { g (189.9 } \pm \\
\text { 39.5). }\end{array}$ \\
\hline & $\begin{array}{l}\text { Lt (machos): } 22.5 \mathrm{~cm} \text { a } 30.0 \mathrm{~cm},(26.6 \pm \\
1.8) .\end{array}$ & $\begin{array}{l}\text { Wt (machos): } 101.0 \mathrm{~g} \text { a } 332.0 \mathrm{~g}(194.7 \pm \\
\text { 42.9). }\end{array}$ \\
\hline
\end{tabular}

\subsection{Relação peso-comprimento e o tipo de crescimento}

$O$ crescimento de machos e fêmeas (sexos agrupados) de $C$. orientale foi de $(\theta=2,9408)$, indicando crescimento alométrico negativo, há um incremento corporal maior em comprimento do que em peso (GURGEL, 2010; GURGEL et al.,2011;NASCIMENTO et al., 2012B). Para a espécie $P$ gracilis o crescimento foi de $\theta=2,827$, do tipo alométrico negativo, indicando um maior incremento em comprimento do que em peso (BARROS, 2009; BARROS et al., 2011; NASCIMENTO et al., 2012b) Santos (2005) estudando a mesma espécie no rio Amambaí, Mato Grosso do Sul (MS), registrou um crescimento do tipo isométrico, Portanto, Gurgel e Mendonça (2001) informam que o tipo de crescimento pode estar condicionado a uma resposta adaptativa ao ambiente.

Para C. menezesi, o crescimento de machos e fêmeas (sexos agrupados) foi de $\theta=2,41$, com o crescimento do tipo alometrico negativo (ARAÚJO, 2012; ARAÚJO et al., 2012; CHELLAPPA et al., 2013; ARAÚJO et al., 2014). Geralmente, ciclídeos macho são maiores e mais pesados do que as 
fêmeas, como conseqüência da evolução comportamental em formação de pares e cuidado parental, o que aumenta o sucesso reprodutivo (CACHO et al., 2006; CACHO et al., 2007). Alguns ciclídeos neotropicais como Cichla monoculus apresenta dimorfismo sexual, em que os machos exibem uma corcunda cefálica durante o período reprodutivo com acumulação de lipídios (CHELLAPPA et al., 2003).

O valor do coeficiente angular de $S$. marmoratus mostrou que a espécie apresenta um crescimento do tipo alométrico negativa $(\theta=2,585)$, ou seja, um maior incremento em comprimento do que em peso. $O$ crescimento do tipo alométrico negativo para $S$. marmoratus, é o mais esperado uma vez que a espécie apresenta o corpo alongado ou serpentiforme (DAMASCENO, 2008; BARROS, 2012; BARROS et al., 2012; BARROS et al., 2013a; BARROS et al., 2013b; CHELLAPPA et al., 2013; BARROS et al., 2014).

O coeficiente angular de $T$. angulatus apresentou um valor de $\theta=1,79$, indicando que a espécie apresenta um crescimento alométrico negativo (ARAÚJO, 2012; ARAÚJO et al., 2012; NASCIMENTO et al., 2012b;CHELLAPPA et al., 2013). Esse resultado indica que há um incremento maior em comprimento do que em peso, que é esperado para espécies com formato do corpo alongado e deprimido lateralmente (PRESTES et al., 2010). Para T. angulatus resultados semelhantes foram registrados (PRESTES et al., 2010; NASCIMENTO et al., 2012).

O coeficiente angular de $H$. pusarum para as fêmeas foi de $\theta=2,0137$, com $r=0,6345$ e para machos foi de $\theta=2,3418$ com $r=0,7260$ (BUENO, 2004; BUENO et al., 2008; PESSOA et al., 2013). A espécie $H$. pusarum apresenta um crescimento do tipo alométrico negativo, ganhando mais incremento em comprimento do que em peso, resultado que é esperado para espécies com formato do corpo alongado e deprimido (PRESTES et al., 2010).

\subsection{Proporção sexual}

A proporção sexual de $C$. orientale foi de $1,5 \mathrm{M}: 1 \mathrm{~F}$, diferindo do esperado (1:1). Os resultados mostram uma predominância de machos $(60,2 \%)$ considerando o período de estudo como um todo, no trecho estudado do rio Assu (GURGEL, 2010; GURGEL et al.,2011;NASCIMENTO et al., 2012B). Para P. gracilis a proporção sexual foi de 1M:1F, (BARROS, 2009; BARROS et al., 2011). Para esta espécie a proporção sexual não diferiu significativamente do esperado, porém em fevereiro, o número de machos foi superior ao de fêmeas (CANTANHÊDE et al., 2007).

A proporção sexual de $P$. brevis observada, foi de 1,2M:1F, diferindo do esperado (1:1). Durante o período de estudo, a proporção entre os sexos foi de $60 \%$ de machos em relação a $40 \%$ de fêmeas (NASCIMENTO, 2006; GURGEL, 2010; GURGEL et al., 2012; NASCIMENTO et al., 2012a). De acordo com Nikolsky (1963), esta proporção varia consideravelmente de espécie para espécie, podendo também variar na mesma população de um ano para outro.

A proporção sexual de $C$. menezesi foi de $1,3 \mathrm{M}: 1 \mathrm{~F}$, com uma ligeira predominância do sexo masculino (57,93\%) em relação ao sexo feminino (42,07\%). No entanto, este diferença não foi estatisticamente significativa no nível 5\% (X2 = 2.51) (ARAÚJO, 2012; ARAÚJO et al., 2012; CHELLAPPA et al., 2013; ARAÚJO et al., 2014). A espécie de C. menezesi apresentou uma razão sexual dentro da esperada, mesmo havendo uma leve predominância de machos, já que a diferença não foi estatisticamente significativa. 
Um total de 179 indivíduos de S. marmoratus foi capturado e observou-se que a população amostrada constituída de quatro tipos diferentes de sexo: machos primários (nascido e funcionam como machos; $n=12$ ), as fêmeas funcionais $(n=126)$, os indivíduos intersexos (com ambos os tecidos gonadais machos e femeas; $n=14$ ) e machos secundários (fêmeas que sofreran inversao sexual para machos; $n=27$ ). Houve um predomínio de fêmeas, durante todo o período de amostragem ( $\chi 2=57,51 ; p=0,0001$ ) (DAMASCENO, 2008; BARROS, 2012; BARROS et al., 2012; BARROS et al., 2013a;BARROS et al., 2013b; CHELLAPPA et al., 2013; BARROS et al., 2014).

A proporção sexual de $T$. angulatus foi de $1 \mathrm{M}: 2 \mathrm{~F}$. Nos meses de julho e dezembro houve um predomínio de machos enquanto as fêmeas predominaram-nos outros meses (ARAÚJO, 2012; ARAÚJO et al., 2012; NASCIMENTO et al., 2012b; CHELLAPPA et al., 2013). No presente estudo houve um predomínio de fêmeas para $T$. angulatus fato este também observado para T. trifurcatus no médio rio Araguaia (MARTINS-QUEIROZ, et al., 2008).

A proporção sexual de $H$. pusarum foi de $1 M: 1,3 F$, sem diferença significativa $(\chi 2=0,8)$ (BUENO, 2004; BUENO et al., 2008; PESSOA et al., 2013). A proporção sexual geralmente não difere, mas pode sofrer variações em diferentes espécies e até mesmo na mesma população em diferentes períodos (VINCENTINI; ARAÚJO 2003; ARAÚJO et al., 2012b; GURGEL et al., 2012).

\subsection{Primeira maturação sexual}

Para C. orientale, o tamanho no qual $50 \%$ das fêmeas e machos que iniciaram o processo de maturação gonadal foi de $7,7 \pm 0,97 \mathrm{~cm}$ e $7,9 \pm 0,77 \mathrm{~cm}$ de comprimento, respectivamente. A determinação do tamanho mínimo de captura deve ser superior aos tamanhos médios de maturação encontrados em $C$. orientale, como forma de tentar garantir que cada indivíduo reproduza pelo menos uma vez antes de sua captura (GURGEL, 2010; GURGEL et al.,2011;NASCIMENTO et al., 2012B).

O comprimento da primeira maturação gonadal para $P$. brevis foi de 19,2 $\pm 0,21 \mathrm{~cm}$ para fêmeas e 18,6 \pm 0,07 cm para machos (NASCIMENTO, 2006; GURGEL, 2010; GURGEL et al., 2012; NASCIMENTO et al., 2012a). Para a espécie Curimatella lepidura (Curimatidae) no reservatório de Juramento, Brasil, comprimento da primeira maturação gonadal foi de $7,7 \mathrm{~cm}$ para fêmeas e 7,1 $\mathrm{cm}$ para os machos (ALVARENGA, 2006). As fêmeas de $C$. menezesi atingem a maturidade sexual com 13,8 cm fêmeas e 17,5 cm machos (ARAÚJO, 2012; ARAÚJO et al., 2012; CHELLAPPA et al., 2013; ARAÚJO et al., 2014). As fêmeas de C. menezesi atingem a maturidade sexual mais cedo do que os machos, mobilizando suas reservas de energia para o processo reprodutivo bem antes dos machos. No Oeste Africano o ciclídeo Chromidotilapia guntheri, atingem a maturidade sexual com tamanho igual para ambos os sexos, refletindo alocação igual de energia para a reprodução. No entanto, o tempo de maturação sexual está intimamente associado com o tamanho do corpo do peixe (BOUSSOU, 2010). Para S.marmoratus o tamanho para o qual 50\% da população de fêmeas exibiram o processo de maturação gonadal foi de $39,5 \mathrm{~cm}$ de comprimento total e para machos secundários foi de 58,5 cm de comprimento total (BARROS et al., 2012; BARROS et al., 2013a;BARROS et al., 2013b; CHELLAPPA et al., 2013; BARROS et al., 2014).

Para T. angulatus foi observado que o valor estimado para a primeira maturação das fêmeas foi de 16,3 cm enquanto e para machos foi de 15,5 cm (ARAÚJO, 2012; ARAÚJO et al., 2012; NASCIMENTO et al., 2012b; CHELLAPPA et al., 2013). Para T. angulatus foi observado que as fêmeas 
maturam primeiro que os machos. Este motivo pode esta relacionada ao fato do $L_{50}$ e $L_{100}$ serem valores adaptáveis às condições ambientais, disponibilidade de recursos e abundância de espécies (VAZZOLER, 1996; GOMIERO et al., 2008).

\subsection{Desenvolvimento das gônadas}

A espécie de $C$. orientale apresentou os quatro estádios de desenvolvimento gonadal: imaturo, em maturação, maturo e esgotado ou desovado (GURGEL, 2010; GURGEL et al.,2011;NASClMENTO et al., 2012B). A utilização de escalas macroscópicas contribui para o conhecimento biológico e auxilia na compreensão do período reprodutivo das espécies (WEST, 1990). A classificação macroscópica dos ovários e testículos de $C$. orientale sugere que ocorre certa padronização ao longo do desenvolvimento gonadal para cada estádio: imaturo, em maturação, maturo e esgotado ou desovado (CÂMARA et al.,2002; CÂMARA, 2004; CHELLAPPA et al,2005; PANDOLFI et al.,2009).

A espécie $P$. gracilis apresentou os três estádios de desenvolvimento gonadal para machos e fêmeas: jovem, em maturação e maduro (BARROS, 2009; BARROS et al., 2011). A escala de maturidade das gônadas desempenhou importante papel na descrição dos fenômenos do ciclo reprodutivo de $P$. gracilis, contudo, a análise histológica é fundamental para uma melhor identificação dos estádios de desenvolvimento das gônadas (SANTOS, 2001; CHELLAPPA et al., 2005). A espécie P.brevis, apresentou os três estádios de desenvolvimento gonadal para os machos: em maturação, maduro e esvaziado, e para as fêmeas apenas dois estádios de desenvolvimento gonadal foram identificados: em maturação e maduro. Não foram considerados os estádios imaturos e esvaziados, por não ter sido capturado nenhum indivíduo fêmea em tais condições (NASCIMENTO, 2006; GURGEL, 2010; GURGEL et al., 2012; NASCIMENTO et al., 2012a).

O estudo macroscópico das gónadas de C. menezesi apresentou os quatro estádios de desenvolvimento gonadal para machos e femeas: imaturo, em maturação, maduro e parcialmente esvaziado (ARAÚJO, 2012; ARAÚJO et al., 2012; CHELLAPPA et al., 2013; ARAÚJO et al., 2014). Estes resultados são consistentes com estudos de outros ciclídeos neotropical, como o acará bandeira, Pterophyllum scalare (DIAS \& CHELLAPPA, 2003), o tucunaré, Cichla monoculus (CHELLAPPA et al., 2003), acará disco, Symphysodon discus (CHELLAPPA et al., 2005), e cará, Cichlasoma orientale (GURGEL et al., 2011).

Para S. marmoratus foi detectada a presença de quatro tipos sexuais, os machos primários (esse tipo sexual apresenta uma característica de fácil diferenciação sendo a única fase em que o órgão reprodutor apresenta-se como um par de testículos); fêmeas (o ovário é diferenciado, sendo identificado como um único cordão que se estende por praticamente todo o comprimento do corpo); intersexo (indivíduos em transição, a gônada é caracterizada pela presença de tecido masculino e feminino) e macho secundário (são os indivíduos que sofreram totalmente o processo de inversão sexual a partir das fêmeas) (BARROS, 2012; BARROS et al., 2012; BARROS et al., 2013a;BARROS et al., 2013b; CHELLAPPA et al., 2013; BARROS et al., 2014). Foi realizada uma análise prévia histológica para determinar o intersexo, uma vez que, no trabalho, as caracteristicas macroscópicas gonadais dos indivíduos capturados, na maioria das vezes, não permitiram a identificação do sexo, exceto em machos primários que apresentaram suas gônadas como um par, um lóbulo direito e outro esquerdo. S. marmoratus é uma espécie hermafrodita sequencial sucessiva, desenvolvendo o tecido gonadal feminino, que é funcionalmente ativo por um ou mais ciclos reprodutivos, e logo após sofre um processo de regressão (LO NOSTRO, 2000; BARROS, 2012). 
Para T. angulatus quatro estádios de desenvolvimento foram encontrados: imaturo, em maturação, maduro e parcialmente esvaziado. Para as fêmeas a frequência de ocorrência dos estádios de maturação gonadal mostra que o estádio imaturo ocorreu nos meses de março e de junho a setembro, o estádio em maturação ocorreu no periodo de abril a outubro e o estádio parcialmente esvaziado e maduro ocorreram apenas no meses de março, abril e maio. Para os machos a frequência de ocorrência dos estádios de maturação gonadal mostra que estádio imaturo ocorreu no periodo de junho a setembro, o estádio em maturação ocorreu nos meses de março a dezembro, o estádio maduro e parcialmente esvaziado ocorreu nos meses de março a maio (ARAÚJO, 2012; ARAÚJO et al., 2012; NASCIMENTO et al., 2012b; CHELLAPPA et al., 2013). Para Hypostomus pusarum ambos os sexos apresentam quatro estádios de desenvolvimento gonadal, sendo: imaturo, em maturação, maduro e esvaziado (BUENO, 2004; BUENO et al., 2008; PESSOA et al., 2013).

\subsection{Fator de condição (K)}

Para C. orientale as variações temporais do fator de condição $(\mathrm{K})$ demonstraram baixa amplitude, onde os maiores valores ocorreram de julho a novembro $(K=0,029 \pm 0,009)$, e os menores a partir de dezembro $(K=0,026 \pm 0,002)$, com um pico em agosto $(K=0,032 \pm 0,008)$ e um valor mais baixo em maio $(K=0,025 \pm 0,001)$. Foi constatada uma relação direta entre o fator de condição e o índice gonadossomático, demonstrando ser um bom indicador do período de desova desta espécie (GURGEL, 2010; GURGEL et al.,2011; NASCIMENTO et al., 2012b). O fator de condição para $P$. gracilis, para sexo agrupado, apresentou os menores valores no período de março a abril e de agosto a setembro, com picos nos meses de janeiro e junho. $O$ fator de condição mostrou um declino durante o período reprodutivo, visto que durante esta fase as reservas energéticas do corpo são mobilizadas para o desenvolvimento das gônadas, que ocupam um grande volume dentro da cavidade abdominal (BARROS, 2009; BARROS et al., 2011; NASCIMENTO et al., 2012b).

Para a espécie $C$. menezesi, os valores de $K$ para fêmeas variando de 1,002 $\pm 0,08-2,485 \pm$ 0,01 , com uma média de 1,045 $\pm 0,075$, e para machos de 1,05 $\pm 0,08-1,478 \pm 0,23$, com uma média de 1.207 × 0,14 (ARAÚJO, 2012; ARAÚJO et al., 2012; CHELLAPPA et al., 2013; ARAÚJO et al., 2014). Os baixos valores de $\mathrm{K}$ pode ser relacionada com a fase pós-reprodutiva, uma vez que há uma redução da sua atividade metabólica e consequente declínio na atividade alimentar (SOUZA, 2008 NORMANDO, 2009). O fator de condição de $S$. marmoratus para sexos agrupados mostrou seu menor valor no mês de agosto e em seguida dois picos, um em dezembro e outro em janeiro (DAMASCENO, 2008; BARROS, 2012; BARROS et al., 2012; BARROS et al., 2013a;BARROS et al., 2013b; CHELLAPPA et al., 2013; BARROS et al., 2014). O fator de condição pode ser definido como o estado de bem estar do peixe, ou seja, como o animal aproveita os recursos disponíveis existentes numa determinada época do ano. É frequentemente utilizado como um indicador do período de desova, uma vez que neste período a intensidade alimentar pode cessar e o fator de condição mostra valores inferiores (CHELLAPPA et al., 1995).

O fator de condição das fêmeas de $T$. angulatus foi menor no mês de março e os machos no mês de setembro (ARAÚJO, 2012; ARAÚJO et al., 2012; NASCIMENTO et al., 2012b; CHELLAPPA et al., 2013). O fator de condição apresentou valores inversamente proporcionais ao IGS. Estes resultados também sugerem que a redução nos valores de $\mathrm{K}$ reflete os custos energéticos do processo reprodutivo de machos e fêmeas (HUNTINGFORD et al., 2001; GOMIERO et al., 
2010). Os valores médios do fator de condição (K) para $H$. pusarum foram $K=0,089 \pm 0,008$ para machos e $K=0,266 \pm 0,034$ para fêmeas. Observou-se um leve declínio durante o curto período de chuva nos meses de janeiro e fevereiro (BUENO, 2004; BUENO et al., 2008; PESSOA et al., 2013). Valores similares aos observados neste trabalho foram observados para Leporinus piau (Fowler, 1941), capturado no açude Marechal Dutra, RN (SILVA FILHO et al., 2012).

\subsection{Fecundidade e tipo de desova}

A fecundidade média de $C$. orientale foi 756, 85 ovócitos por lote e indicou uma fecundidade proporcional ao seu tamanho corporal (GURGEL, 2010; GURGEL et al.,2011;NASCIMENTO et al., 2012B). Como foram observados ovócitos em diferentes tamanhos sugere-se que o mecanismo de desenvolvimento ovocitário seja sincrônico em mais de dois grupos, tipo de desenvolvimento que caracteriza desova múltipla ou parcelada (VAZZOLLER, 1996). A desova parcelada de C. orientale acompanhou o regime pluviométrico da região, portanto a espécie está ajustada e bem adaptada às características ambientais da região semiárida (CHELLAPA et al., 2003).

Para P. brevis a fecundidade absoluta apresentou uma amplitude de 52,512 a 98,418 ovócitos vitelogênicos, com média de 75,465. A espécie apresentou desova total, confirmada através da distribuição de frequência relativa do diâmetro dos ovócitos vitelogênicos (NASCIMENTO, 2006; GURGEL, 2010; GURGEL et al., 2012; NASCIMENTO et al., 2012a).

Muitas espécies de peixes possuem desova parcelada para melhor aproveitar o alimento disponível, evitando a competição alimentar na fase larval. Enquanto outras espécies de peixes, os ovócitos são liberados em um só lote, caracterizando a desova total (LOWE-McCONNEI, 1987). A fecundidade média de $C$. menezesi apresentou uma amplitude de $128( \pm 1,41)$ e $749( \pm 31,81)$, com uma média de 372 ( \pm 10,41) ovócitos maduros (ARAÚJO, 2012; ARAÚJO et al., 2012; CHELLAPPA et al., 2013; ARAÚJO et al., 2014). A fecundidade é considerada baixa e a desova é parcial. A fecundidade baixa, e um característica das espécies que exibem período reprodutivo prolongado com cuidado parental (CHELLAPPA et al., 2003; OLELE, 2010). A fecundidade aumenta com o aumento do tamanho do corpo em $C$. menezesi. Nos peixes, a fecundidade é positivamente correlacionada com o tamanho do corpo, devido à disponibilidade de energia para a produção de oócitos (PATIMAR \&. MOHAMMADZADEH, 2011).A fecundidade absoluta de $P$. rhomboides variou 1096-10 137 ovócitos maduros, com um valor médio de 6188 ( \pm 367$)$.

Para S.marmoratus a fecundidade das fêmeas com o comprimento total médio (de 42,5 $\mathrm{cm}$ ) variou de 311-313 ovócitos maduros, enquanto que o de fêmeas maiores de $(51 \mathrm{~cm})$ variou de 621 - 627 ovócitos maduros. Os cortes histológicos de ovário de S. marmoratus, mostrou a presença de ovócitos maduros e reserva ovogonia que caracterizam a desova do tipo total (DAMASCENO, 2008; BARROS, 2012; BARROS et al., 2012; BARROS et al., 2013a;BARROS et al., 2013b; CHELLAPPA et al., 2013; BARROS et al., 2014).

A fecundidade absoluta de ovários de T. angulatus variou de 3.072 a 11.000 ovócitos, sendo a fecundidade absoluta média de 6.648 ( \pm 205$)$. Foi observada desova total, uma vez que apresentou células ovocitárias de lotes existentes nos ovários. Os ovócitos foram eliminados de uma só vez durante o período de desova (ARAÚJO, 2012; ARAÚJO et al., 2012; NASCIMENTO et al., 2012b;CHELLAPPA et al., 2013). A fecundidade de T.angulatus foi de 6.648 ovócitos quando com- 
parada com a de $T$. trifurcatus (7.920 ovócitos) apresentou valores próximos, mas quando comparada com outros Characiformes como: Astyanax bimaculatus, 31.720 (SATO et al., 2006); Oligosarcus robustus, 40.219 (NUNES et al., 2004) é considerada baixa. A fecundidade é uma característica específica e está adaptada às condições do ciclo de vida da espécie, variando com o crescimento, densidade populacional, disponibilidade de alimento e taxa de mortalidade (BAGENAL; BRAUM, 1978; FAWOLE; ARAWOMO, 2000; SATO et al., 2003), no entanto essas característica podem explicar essa diferença na taxa de fecundidade entre as espécies. T. angulatus apresentou desova total, assim o presente resultado difere do descrito para $T$. guentheri, que apresenta desova parcelada (GODINHO, 1994).

A fecundidade absoluta de $H$. pusarum, variou de 536 a $1075(756,85 \pm 164,53)$ ovócitos vitelogênicos (BUENO, 2004; BUENO et al., 2008; PESSOA et al., 2013). A fecundidade é uma tática reprodutiva específica e está adaptada às condições do ciclo de vida da espécie, variando com o crescimento, densidade populacional, tamanho corporal, disponibilidade de alimento e taxa de mortalidade, no entanto essas características podem explicar essa diferença na taxa de fecundidade entre as espécies (WEST, 1990; LOWERRE-BARBIERI et al., 1996; CHELLAPPA et al., 2005).

\subsection{Período reprodutivo}

Para C. orientale o aumento da relação gonadossomática entre outubro e fevereiro reflete um aumento do peso das gônadas, sendo possível inferir que o período reprodutivo de $C$. orientale seja durante esta época, coincidindo com o início do período das chuvas e consequentemente a elevação do nível d'água do rio (GURGEL, 2010; GURGEL et al.,2011;NASCIMENTO et al., 2012B). Vários estudos sobre a biologia reprodutiva de peixes têm apontado o período de cheia como sendo a fase do ciclo hidrológico onde a maioria das espécies reproduz-se assegurando aos filhotes maior disponibilidade de concentração do oxigênio, minimizando os riscos de predação da prole devido ao aumento de abrigos e maximizando a quantidade de alimento (VAZZOLLER, 1996; SANTOS, 2006; CHELLAPPA et al., 2009; FAVERO et al., 2010).

Para $P$. gracilis variação mensal do IGS evidencia que machos e fêmeas apresentam maior atividade reprodutiva no período de janeiro a maio de 2009, com um declínio no mês de junho de 2009 (BARROS, 2009; BARROS et al., 2011). Quando relacionado o IGS com a pluviosidade da área de estudo, observa-se que há uma correlação positiva. Resultado semelhante foi encontrado para a mesma espécie no rio Amambaí, Mato Grosso, onde o IGS apresentou uma correlação positiva com o índice pluviométrico (SANTOS et al., 2005). Em relação aos valores de IGS de $P$. brevis, foi observado que as fêmeas apresentaram valores mais elevados do que os machos (NASCIMENTO, 2006; GURGEL, 2010; GURGEL et al., 2012; NASCIMENTO et al., 2012a). Os valores do IGS mais elevados para as fêmeas foram relatados para Prochilodus scrofa, demonstrando que o aumento de volume dos ovários durante o processo de maturação gonadal ocorre de modo acentuado (GODOY, 1959). Estudos com diversas espécies relataram ocorrência de valores mais elevados do IGS no estádio maduro e inferiores após a desova (RODRIGUES et al., 1995; AGOSTINHO et al., 1984).

Neste estudo o índice gonadossomático mostrou-se adequado como indicador do período reprodutivo dessa espécie. Para $C$. menezesi, os valores de IGS das fêmeas variaram de 0,273 ( \pm $0,01)$ a 4,584 $( \pm 0,06)$, com uma média de $2,448( \pm 0,74)$. As fêmeas apresentaram maior IGS nos meses de março a maio e de setembro a novembro. Os valores de IGS dos machos variou de 0,136 $( \pm 0,08)$ a $1,308( \pm 0,10)$, com uma média de $0,9192( \pm 0,11)$. Os machos apresentaram maior IGS 
nos meses de março a maio e de julho a setembro. C. menezesi apresentou um período reprodutivo prolongado de março a setembro, com picos de março a maio e de julho a setembro (ARAÚJO, 2012; ARAÚJO et al., 2012; CHELLAPPA et al., 2013; ARAÚJO et al., 2014). O IGS é útil para identificar o período reprodutivo total ou os picos de atividade reprodutiva parciais. No entanto, além de IGS, é necessário incluir os resultados de análises histológicas das gônadas para interpretar corretamente o período de desova.

O IGS da espécie S. marmoratus para sexos agrupados apresentou os maiores valores nos meses de julho a agosto e nos meses seguintes uma diminuição gradativa dos valores mostrando seu menor valor no mês de janeiro (DAMASCENO, 2008; BARROS, 2012; BARROS et al., 2012; BARROS et al., 2013a;BARROS et al., 2013b; CHELLAPPA et al., 2013; BARROS et al., 2014).

A análise mensal, dos valores do índice gonadossomático demonstrou que o período reprodutivo foi curto determinado entre os meses de julho a agosto, meses que mostraram os valores mais altos. O Índice gonadossomático representa a relação entre o peso das gônadas e o peso do indivíduo, e demonstra o estado funcional das gônadas através da porcentagem que estas representam do peso do individuo. Este índice pode ser considerado como melhor indicador do período de desova (VAZZOLER, 1996).

A variação mensal média do IGS das fêmeas de $T$. angulatus apresentou valores mais altos no mês de março e os machos no mês de setembro. Os dados da análise do IGS e dos estádios de maturação gonadal, sugerem que o período de desova de $T$. angulatus ocorre em março a maio acompanhando o período de chuva da região (ARAÚJO, 2012; ARAÚJO et al., 2012; NASCIMENTO et al., 2012b;CHELLAPPA et al., 2013). Os valores médios mais elevados do IGS de T. angulatus ocorreu no mês de março a maio durante o início do período chuvoso. Para T. trifurcatus encontrado no médio Rio Araguaia o pico da atividade de reprodução da espécie em questão coincide com a época de chuva com alto nível da água, ou seja, de novembro a janeiro fato este também observado para outros Characiformes como P. amazonica (MARTINS-QUEIROZ, 2008).

Para H. pusarum o menor valor do IGS para os machos foi de 0,483 , registrado no mês de julho de 2012 e o maior foi 7,502 $(3,033 \pm 2,0)$ no mês de fevereiro de 2012 . O menor valor de IGS para as fêmeas foi de 3,408 em julho de 2011 e o maior de 10,533(6,200 $\pm 2,5)$ em fevereiro de 2012. Foi observado que os valores do IGS de fêmeas apresentaram maiores valores no período de precipitação pluviométrica (BUENO, 2004; BUENO et al., 2008; PESSOA et al., 2013). Em regiões tropicais, onde as variações estacionais de temperatura são pouco significativas, a precipitação pluviométrica desempenha um papel decisivo na determinação de ciclos reprodutivos (PARSONS et al., 1984; CHELLAPPA et al., 2009). As fêmeas apresentaram picos de IGS em janeiro a abril, indicando o período reprodutivo da espécie, que coincidiu com a época chuvosa da região. O período reprodutivo de $H$. pusarum registrado neste trabalho corrobora com os resultados de um trabalho anterior (BUENO et al., 2006).

\subsection{Estratégias reprodutivas}

Os peixes apresentam três tipos de estratégias reprodutivas, $K, r$ e sazonal, dentre essas estratégias encontramos um conjunto de táticas (tamanho do corpo, proporção sexual, relação peso-comprimento, primeira maturação sexual (L50), estádios de desenvolvimento gonadal, fator de condição, fecundidade, tipo de desova e período reprodutivo (Tabela 2). 
Tabela 2: Táticas e Estrátegias reprodutivas de peixes de água doce do Estado do Rio Grande do Norte.

\begin{tabular}{|c|c|c|c|c|c|c|c|}
\hline \multirow{2}{*}{ Táticas Reprodutivas } & \multicolumn{2}{|c|}{ Estratégia Reprodutiva K } & \multicolumn{3}{|c|}{$\begin{array}{l}\text { Estratégias Reprodutiva } \\
\text { Estratégia Reprodutiva sazonal }\end{array}$} & \multicolumn{2}{|c|}{ Estratégia Reprodutiva r } \\
\hline & C. orientale & S. marmoratus & C. menezesi & P. brevis & H. pusarum & P. gracilis & T. angulatus \\
\hline Tamanho dos peixes & $\begin{array}{l}\text { Intermediário (machos } \\
\text { maiores) }\end{array}$ & $\begin{array}{l}\text { Grande (machos secundários } \\
\text { maiores) }\end{array}$ & $\begin{array}{l}\text { Intermediário (machos } \\
\text { maiores) }\end{array}$ & Grande (fêmeas miores) & $\begin{array}{l}\text { Intermediário (fềmeas e } \\
\text { machos com } \\
\text { comprimentossemelhantes) }\end{array}$ & Pequeno & Pequeno (fêmeas miiores) \\
\hline Proporção sexual & 1,5M:1F & $1 \mathrm{M}: 4,6 \mathrm{~F}$ & $1.3 \mathrm{M}: 1 \mathrm{~F}$ & $1,2 \mathrm{M}: 1 \mathrm{~F}$ & $1 \mathrm{M}: 1,3 \mathrm{~F}$ & 1M:1F & $1 \mathrm{M}: 2 \mathrm{~F}$ \\
\hline $\begin{array}{l}\text { Relação peso- } \\
\text { comprimento e o tipo de } \\
\text { crescimento }\end{array}$ & Alométrico negativo & Alométrico negativo & Isométrico & - & Alométrico negaivo & Alométrico negativo & Alométrico negativo \\
\hline $\begin{array}{l}\text { Primeira maturação sexual } \\
\text { (L50) }\end{array}$ & $\begin{array}{c}7,7 \pm 0,97 \mathrm{~cm} \mathrm{fèmeas} \mathrm{e} 7,9 \\
\pm 0,77 \mathrm{~cm} \text { para machos }\end{array}$ & $\begin{array}{c}39,5 \pm 0,15 \text { cm fèmeas e } \\
58,5 \pm 0,8 \text { cmpara macho } \\
\text { secundário }\end{array}$ & $\begin{array}{l}13,8 \mathrm{~cm} \text { fêmeas e } 17,5 \mathrm{~cm} \\
\text { machos }\end{array}$ & $\begin{array}{c}19,2 \pm 0,21 \text { cm fèmeas } \mathrm{e} \\
18,6 \pm 0,07 \mathrm{~cm} \text { para machos }\end{array}$ & - & - & $\begin{array}{l}16,3 \mathrm{~cm} \text { fêmeas e } 15,5 \mathrm{~cm} \text { para } \\
\text { machos }\end{array}$ \\
\hline $\begin{array}{l}\text { Estádios de } \\
\text { desenvolvimento gonadal }\end{array}$ & $\begin{array}{l}\text { Imaturo, em maturacâao, } \\
\text { maturaçăo, em desova }\end{array}$ & $\begin{array}{l}\text { Machos primários; } \\
\text { fêmeas,intersexo e macho } \\
\text { secundário }\end{array}$ & $\begin{array}{l}\text { Imaturo, em maturação, } \\
\text { maduro e parcialmente } \\
\text { esvaziado }\end{array}$ & $\begin{array}{l}\text { Machos: Em maturação, } \\
\text { maduro e esvaziado }\end{array}$ & $\begin{array}{l}\text { imaturo, em maturacăo, } \\
\text { maduro e esvaziado }\end{array}$ & $\begin{array}{l}\text { Jovem, em maturaçầo e } \\
\text { maduro }\end{array}$ & $\begin{array}{l}\text { Imaturo, em maturacăao, madưo e } \\
\text { parcialmente esvaziado }\end{array}$ \\
\hline Fator de condição (K) & $\begin{array}{c}\text { Maiores valores ocorreram } \\
\text { de julho a novembro }(\mathrm{K}= \\
0,029 \pm 0,009)\end{array}$ & $\begin{array}{l}\text { Mostrou baixo no mês de } \\
\text { agosto e como picos em } \\
\text { dezembro e janeiro }\end{array}$ & $\begin{array}{l}\text { Fêmeas variou de } 1,002 \pm 08 \\
\text { e 2,485 } \pm 0,01 \text {. Machos } 1,05 \\
\pm 0,08 \text { e } 1,478 \pm 0,23\end{array}$ & $\begin{array}{c}\text { Maiores valores ocorreu de } \\
\text { outubro a dezembro }(\mathrm{K}= \\
0,012 \pm 0,001)\end{array}$ & $\begin{array}{c}\mathrm{K}=0,089 \pm 0,008 \text { para } \\
\text { machos e } \mathrm{K}=0,266 \pm 0,034 \\
\text { para femeas }\end{array}$ & $\begin{array}{l}\text { Mostra dois picos nos meses } \\
\text { de janeiro e junho }\end{array}$ & $\begin{array}{l}\text { Para as fềmeas foi menor no mês } \\
\text { de março e para os machos no } \\
\text { més de setembro }\end{array}$ \\
\hline $\begin{array}{l}\text { Fecundidade e tipo de } \\
\text { desova }\end{array}$ & $\begin{array}{l}536 \text { a } 1075 \text { ovocitos; } \\
\text { Desova parcelada }\end{array}$ & $\begin{array}{l}311 \text { a } 627 \text { ovocitos; Desova } \\
\text { total }\end{array}$ & $\begin{array}{c}128( \pm 1,41) \text { a } 749( \pm 31,81) \\
\text { ovocitos }\end{array}$ & 52,512 a 98,418 ovocitos & $\begin{array}{c}536 \text { a } 1075(756,85 \pm 164,53) \\
\text { ovócitos }\end{array}$ & - & $\begin{array}{l}3.072 \text { a } 11.000 \text { ovócitos; Desova } \\
\text { total }\end{array}$ \\
\hline IGS e Período reprodutivo & $\begin{array}{l}\text { O IGS mostrou dois picos } \\
\text { reprodutivos, durante época } \\
\text { chuvosa. }\end{array}$ & $\begin{array}{l}\text { O IGS mostrou para dois } \\
\text { picos nos meses de julho a } \\
\text { agosto. }\end{array}$ & $\begin{array}{c}\text { Periodo reprodutivo } \\
\text { prolongado de março a } \\
\text { setembro, compicos de } \\
\text { março a maio e de julho a } \\
\text { setembro. }\end{array}$ & $\begin{array}{l}\text { O periodo reprodutivo } \\
\text { possivelmente ocorreu } \\
\text { durante dezembro a mio. }\end{array}$ & $\begin{array}{l}\text { o menor valor de IGS para os } \\
\text { machos foi no mês de julho e } \\
\text { o maior foi de fevereiro e para } \\
\text { as fêmeas o menor valor foi } \\
\text { em julho e o maior em } \\
\text { fevereiro. }\end{array}$ & $\begin{array}{l}\text { o IGS mostra miores } \\
\text { valores durante a estaçăo } \\
\text { chuvosa de março a maio. }\end{array}$ & $\begin{array}{l}\text { O IGS mostrou um pico o mês de } \\
\text { março para as fêmeas e no més } \\
\text { de setembro para machos. }\end{array}$ \\
\hline
\end{tabular}

\section{CONCLUSÃO}

Como pode-se verificar nos estudos analisados, a diversidade de táticas e estratégias que as diferentes espécies de peixes do bioma Caatinga apresentam são de extrema importância para o conhecimento da biología reprodutiva. As informações como proporção sexual, relação pesocomprimento, tamanho mínimo de captura, desenvolvimento gonadal e fecundidade fornecem subsídios ao gerenciamento adequado dos recursos aquáticos, além de servir como base para novos estudos sobre as espécies. Os resultados indicam que as espécies $C$. orientale e $S$. marmoratus podem ser considerados como estrategistas de equilibrio $K$, enquanto $C$. menezesi, $P$. brevis e $H$. pusarum podem ser considerados como estrategistas sazonais. $P$. gracilis e $T$. angulatus podem ser considerados como estrategista $r$. C. orientale e $S$. marmoratus equilibrio $K$ e mostram que estão mais adptadas ao clima semiárido. Uma vez que alguns trabalhos não providenciam informações completas em relação às táticas reprodutivas de peixes, essas conclusões podem ser consideradas preliminares. Contudo, o presente estudo fornece informações sobre os aspectos reprodutivos dos peixes neotropicais de água doce do Rio Grande do Norte, Brasil.

\section{AGRADECIMENTOS}

Os autores agradecem a Coordenação de Aperfeiçoamento de Pessoal de Nível Superior (Capes) e ao Conselho Nacional de Desenvolvimento Científico Tecnológico (CNPq), pelas concessões de bolsas para realização da pesquisa. 


\section{REFERENCIAS BIBLIOGRÁFICAS}

1. ALVARENGA, E.R., BAZZOLI, N., SANTOS, G.B., RIZZO, E. Reproductive biology and feeding of Curimatella lepidura (Eigenmann \& Eigenmann) (Pisces, Curimatidae) in Juramentoreservoir, Minas Gerais, Brazil. Revista Brasileira de Zoologia, v.23, n.2, p. 314-322, 2006.

2. ARAÚJO, A.S. Composição ictiofaunística e estratégias reprodutivas de quatro espécies de peixes nativos da bacia hidrográfica Piranhas-Assu do bioma Caatinga, RN, Brasil. Tese de Doutorado, Universidade Federal do Rio Grande do Norte, p. 235, 2012.

3. ARAÚJO, A.S., Nascimento, W.S., YAMAMOTO, M.E., CHELLAPPA, S. Temporal dynamics of reproduction of the Neotropical fish, Crenicichla menezesi (Perciformes: Cichlidae). The Scientific World Journal, v. 2012, p. 1-10, 2012a.

4. ARAÚJO, A.S., Lima, L.T.B., Nascimento, W.S., YAMAMOTO, M.E., CHELLAPPA, S. Características morfométricas-merísticas e aspectos reprodutivos da sardinha de água doce, Triportheus angulatus (Osteichthyes: Characiformes) do rio Acauã do bioma Caatinga. Biota Amazônia, v. 2, p. 59-73, 2012b.

5. ARAÚJO, A.S., OLIVEIRA, J.C.S., BARROS, N.H.C., YAMAMOTO, M.E., CHELLAPPA, S. Dinâmica do comportamento territorial de Crenicichla menezesi (Osteichthyes: Perciformes: Cichlidae). Biota Amazônia, v. 4, p. 37-44, 2014.

6. BAGENAL, T.B., BRAUM, E. Eggs and early life history. In Bagenal, T. (ed). Methods for assessment of fish production in freshwater,. IBP (int. Biol. Programme) Handb, v. 3, p. 165201, 1978.

7. BARROS, N.H.C., SOUZA, A.A., CHELLAPPA, S. Histological Aspects of Gonad Development in the Diandric Protogynous Sequential Hermaphrodite Fish Synbranchus marmoratus (Osteichthyes: Synbranchidae). In: José Rosa Gomes; Sathyabama Chellappa. (Org.). Biology of Semiarid Tropical Fish. 1ed.New York, USA: Nova Scientific Publishers, v. 1, p. 35-48, 2014.

8. BARROS, N.H.C., SOUZA, A.A., CHELLAPPA, S. Seasonal changes in condition factor, gonadossomatic and hepatosomatic indices of the protogynous marbled swamp eel, Synbranchus marmoratus. Animal Biology Journal, v. 4, p. 15-25, $2013 a$.

9. BARROS, N.H.C., Nascimento, W.S., ARAÚJO, A.S., ARAUJO, A., CHELLAPPA, S. Biologia reprodutiva do peixe muçum, Synbranchus marmoratus Bloch, 1975 no açude Marechal Dutra, Rio Grande do Norte, Brasil. Biota Amazônia, v. 3, p. 39-47, 2013b.

10. BARROS, N.H.C. Estratégia reprodutiva do peixe hermafrodita mussum, Synbranchus marmoratus em um açude do Rio Grande do Norte. Dissertação de Mestrado em Programa de Pós-Graduação em Ciências Biológicas, Universidade Federal do Rio Grande do Norte, p. 94, 2012.

11. BARROS, N.H.C., SOUZA, A.A., CHELLAPPA, S. Histological aspects of gonad development in the Diandric Protogynous Sequential Hermaphrodite fish Synbranchus marmoratus (Osteichthyes: Synbranchidae). Animal Biology Journal, v. 3, p. 159-172, 2012.

12. BARROS, N.H.C., NASCIMENTO, W.S., ARAÚJO, A.S.; GURGEL, L.L.; CHELLAPPA, S. Aspectos reprodutivas de Pimelodella gracilis (Valenciennes, 1835) (Osteichthyes: Pimelodidae) do açude da Ecoregião Caatinga. Biota Amazônia, v. 1, n. 2, p. 61 - 69, 2011.

13. BARROS, N.H.C. Biologia reprodutiva do niquim, Pimelodella gracilis (Valenciennes, 1835) 
(Osteichthyes: Pimelodidae) no açude Marechal Dutra, Rio Grande do Norte. Monografia de Conclusão de Curso, Graduação em Bacharelado em Aquicultura, Universidade Federal do Rio Grande do Norte, p.79, 2009.

14. BOUSSOU, C.K., EDIA, E.O., KONAN, F.K., OUATTARA, M., GERMAIN, G. Reproductive biology of Chromidotilapia guntheri (Sauvage, 1882) (Cichlidae, Perciformes) in four coastal rivers (Ehania, No'e, Soumi'e and Eholi'e) of C^ote d'Ivoire in WestAfrica. Knowledge and Management of Aquatic Ecosystems, v. 3, p. 396, 2010.

15. BUENO, R.M.X., CHELLAPPA, S., CHELLAPPA, N.T. Período reprodutivo do cascudo, Hypostomus pusarum (Starks) (Osteichthyes, Loricariidae) e limnologia do açude Marechal Dutra no semiárido Brasileiro. Revista Nordestina de Biologia, v. 19, p. 15-27, 2008.

16. BUENO, R.M.X. Biologia reprodutiva do cascudo, Hypostomus pusarum (Starks, 1913) (Osteichthyes: Loricariidae) no açudo Marechal Dutra, Acari, RN. Dissertação de Mestrado em Ecologia, Universidade Federal do Rio Grande do Norte, p.137, 2004.

17. CACHO, M.S.R.F., CHELLAPPA, S., YAMAMOTO, M.E. Efeitos da experiência de machos no sucesso reprodutivo em acara bandeira, Pterophyllum scalare Lichtenstein, 1823 (Osteichthyes, Cichlidae). Revista Brasileira de Zoociências, v. 9, p. 41-47, 2007.

18. CACHO, M.S.R.F., CHELLAPPA, S., YAMAMOTO, M.E. Reproductive success and female preference in the amazonian cichlid angel fish, Pterophyllum scalare (Lichtenstein, 1823). Neotropical Ichthyology, Porto Alegre, RS, v. 4, n.1, p. 87-91, 2006.

19. CANTANHÊDE, G., ANTONIO C.L.C., ÉDER, A.G. Biologia reprodutiva de Hexanematichthys proops (Siluriformes, Ariidae) no litoral ocidental maranhense. Iheringia, Série Zoologia, v. 97, n.4, p. 498-504, 2007.

20. CHELLAPPA, S., CACHO, M.S.R.F., VOLPATO, G.L. Mate Selection and Reproductive success in the Amazonian angelfish, Pterophyllum scalare (Osteichthyes: Cichlidae). Biology of Semiarid Tropical Fish, Editores: José Rosa Gomes \& Sathyabama Chellappa, Nova Science Publishers, New York, USA. 2014. pp. 49-58.

21. CHELlAPPA, S., Nascimento, W.S., BARROS, N.H.C., ARAúJO, A.S., CHELLAPPA, N.T. Reproductive characteristics and strategies of freshwater fish species from the semiarid region of Brazil. Animal Biology Journal, v. 4, p. 85-114, 2013.

22. CHELLAPPA, S., BUENO, R.M.X., CHELLAPPA, T., CHELLAPPA, N.T., Val, V.M.F.A. Reproductive seasonality of the fish fauna and limnoecology of semiarid Brazilian reservoirs. Limnologica, $v$. 39, n. 4, p. 325-329, 2009.

23. CHELLAPPA, S., CÂMARA, M.R., VERANI, J.R. Ovarian development in the Amazonian red discus, Symphysodon discus Heckel (Osteichthyes: Cichlidae). Brazilian Journal of Biology, v. 65, n. 4, p. 609-616, 2005.

24. CHELLAPPA, S., CHELLAPPA, N.T. Ecology and reproductive plasticity of the Amazonian cichlid fishes introduced to the freshwater ecosystems of the semiarid Northeastern Brazil. p. 49 - 57. In: Advances in Fish and Wildlife Ecology and Biology, v. 3, KAUL, B. L. (Ed), New Delhi: Daya Publishing House, p. 317, 2004.

25. CHELLAPPA, S., CÂMARA, M.R., CHELLAPPA, N.T. Ecology of Cichla monoculus (Osteichthyes: Cichlidae) from a reservoir in the semi-arid region of Brazil. Hydrobiologia, v. 504, p. 267-273, 2003. 
26. CHELLAPPA, S., YAMAMOTO, M.E., CACHO, M.S.R.F. Reproductive behaviour and ecology of two species of Cichlid fishes. In: AL Val; VMF Val (Ed). Biology of Tropical Fishes. p. 113 - 126, 1999.

27. CHELLAPPA, S., HUNTINGFORD, F.A., STRANG, R.H., THOMSON, R.Y. Condition factor and hepatosomatic index as estimates of energy status in male three-spined stickleback. Journal of Fish Biology, v. 47, n. 5, p. 775-787, 1995.

28. DAMASCENO, D.N.F. Biologia reprodutiva do mussum, Synbranchus marmoratus, Bloch, 1795 (Osteichthyes: Synbranchidae) do açude Marechal Dutra, RN. Monografia de Conclusão de Curso, Graduação em Bachalerado em Aqüicultura,Universidade Federal do Rio Grande do Norte, p. 45, 2008.

29. DORIA, C.R.C., QUEIROZ, L.J. A pesca comercial das sardinhas (Triportheus spp.) desembarcadas no mercado pesqueiro de Porto Velho, Rondônia (1990-2004): produção pesqueira e perfil. Biotemas, n. 21, v. 3, p. 107 - 115, 2008.

30. FAVERO, J.M., POMPEU, P. S., PRADO-VALLADARES, A. C. Biologia reprodutiva de Heros efasciatus Heckel, 1840 (Pisces, Cichlidae) na Reserva de Desenvolvimento Sustentável Amanã, AM, visando seu manejo sustentável. Acta Amazônica, v. 40, n. 2, p. 373-380, 2010.

31. FAWOLE, O.O., ARAWOMO, G.A.O. Fecundity of Sarotherodon galilaeus (Pisces:Cichlidae) in the Opa reservoir, Ile-Ife, Nigeria. Revista de Biologia Tropical, 48: 201-204, 2000.

32. FILHO, G.B.N. Diversidade Ictiológica e os Aspectos Limnológicos do Açude Cruzeta, Rio Grande do Norte. Trabalho de Conclusão de Curso, Graduação em Bachalerado em Aqüicultura, Universidade Federal do Rio Grande do Norte, p.52, 2007.

33. FROESE, R. Cube law, condition factor and weightlength relationships: history, meta-analysis and recommendations. Journal of Applied Ichthyology, v. 22, p. 241-253, 2006.

34. FROESE, R. Length-weight relationships for 18 less-studied species. Journal of Applied Ichthyology, v. 14, p. 117-118, 1998.

35. GODINHO, H.M. Biologia reprodutiva da piaba-facão, Triportheus guentheri (Characiformes, Characidae) e o manejo hidrológico da represa de Três Marias. Revista Brasileira de Biologia, v. 54, n. 515-524, 1994.

36. GODINHO, H.P., RIBEIRO, D.M. Maturidade sexual de curimbatás, Prochilodus scrofa (Pisces, Teleostei) em viveiros. Arquivos Brasileiros de Medicina Veterinária e Zootecnia, v. 37, p. 349357, 1985.

37. GODOY, M.P. Age, growth, sexual maturity, behavior, migration, tagging and transplantation of curimbatá (Prochilodus scrofa Steindachner, 1881) of Mogi Guassú river, São Paulo State, Brasil. Anais da Academia Brasileira de Ciências, v. 31, p. 447-477, 1959.

38. GOMIERO, L.M., VILLARES-JUNIOR, G.A., BRAGA F.M.S. Relação peso-comprimento e fator de condição de Oligosarcus hepsetus (Cuvier, 1829) no Parque Estadual da Serra do Mar, Núcleo Santa Virgínia, Mata Atlântica, estado de São Paulo, Brasil. Biota Neotropica, v. 10, n. 1, p. 101105, 2010.

39. GURGEL, L.L., VERANI, J.R., CHELLAPPA, S. Reproductive ecology of Prochilodus brevis an endemicfish from the semiarid region of Brazil. The Scientific World Journal, Volume 2012, (Ecology Domain) Article ID 810532, 1-7. 2012. 
40. GURGEL, L.L., VERANI, J.R., CAMARA, F.R.A., BARROS, N.H.C., CHELLAPPA, S. Ecologia reprodutiva de Cichlasoma orientale (Osteichthyes: Cichlidae), um peixe endêmico do semiárido brasileiro. Biota Amazônia, v. 1, p. 41-51, 2011.

41. GURGEL, L.L. Ictiofauna do semiárido Potiguar, Nordeste do Brasil: Composição, riqueza e ecologia reprodutiva de espécies endêmicas. Tese (Doutorado em Ecologia e Recursos Naturais), Universidade Federal de São Carlos, São Paulo, p.116, 2010.

42. GURGEL, H.C.B., MENDONÇA. V.A. Estrutura populacional de Astyanax bimaculatus vittatus (Castelnau, 1855) (Characidae, Tetragonopterinae) do Rio Ceará Mirim, Poço Branco, RN. Revista Ceres, Viçosa, v. 48, n. 276, p.159-168, 2001.

43. HUNTINGFORD, F.A., CHELLAPPA, S., TAYLOR, A.C., STRANG, R.H.C. Energy reserves and reproductive investment in male three spined sticklebacks, Gasterosteus aculeatus. Ecology of Freshwater Fish, v. 10, n. 2, p. 111-117, 2001.

44. JOBLING, M. Environmental factors and rates of development and growth. In: Handbook of fish biology and fisheries, Fish Biology. P. J. Hart, J. D. Reynolds (Eds). Blackwell Publishing Ltd, Oxford, v. 1, pp. 97-122, 2008.

45. KING, J.R., MCFARLANE, G.A. Marine fish life history strategies: applications to fishery management. Fisheries Management and Ecology, v. 10, p. 249-264, 2003.

46. LO NOSTRO, F.L. Espermatogénesis, ciclo anual e inducción hormonal de la espermiación en el pez protoginico diandrico, Synbranchus marmoratus, Bloch, 1795 (Teleostei, Synbranchidae). Tese de Doutorado, Universidade de Buenos Aires, Argentina, p. 170, 2000.

47. LOWERRE-BARBIERI, S.K., CHITTENDEN JR, M.E., BARBIERI, L.R. The multiple spawning pattern of weakfish in the Chesapeake Bay and Middle Atlantic Bight". Journal of Fish Biology, v. 48, n. 6, p. 1139-1163, 1996.

48. LOWE-MCCONNELL. Ecological studies in trpical fish communities. Cambridge: University Press, 1987.

49. LUNDBERG, J.G., MARSHALL, L.G., GUERRERO, J., HORTON, B.M.C.S.L. MALABARBA, M.C.S.L.,WESSELINGH, F. The stage for neotropical fish diversification: A history of tropical South America rivers. p. 13-48. In: Malabarba, L. R., R. E. Reis, R. P. Vari, Z. M. S. Lucena \& C. A. S. Lucena (Eds.). Phylogeny andClassification of Neotropical Fishes. Porto Alegre, EDIPUCRS, p. 603, 1998.

50. MARTINS-QUEIROZ, M.F., MATEUS, F.L., GARUTTI, V., VENERE, P.C. Reproductive biology of Triportheus trifurcatus (Castelnau, 1855) (Characiformes: Characidae) in the middle river Araguaia, MT Brazil. Neotropical Ichthyology, v. 6, p. 231-236, 2008.

51. MENESCAL, R.A. Efeitos da introdução da tilápia do Nilo, Oreochromis niloticus, (Linnaeus, 1758) sobre o desembarque pesqueiro no açude Marechal Dutra, Acari,RN. Dissertação de Mestrado, Universidade Federal do Rio Grande do Norte, Rio Grande do Norte, Brasil. p. 50, 2002.

52. MORENO, T., CASTRO, J.J., SOCORRO, J. Reproductive biology of the sand smelt Atherina presbyter Cuvier, 1829 (Pisces: Atherinidae) in the central-east Atlantic. Fisheries Research , v. 72, p. 121-131, 2005.

53. NASCIMENTO, M.M., Nascimento, W.S., CHELLAPPA, N.T., CHELLAPPA, S. Biologia reprodutiva 
do curimatã comum, Prochilodus brevis (Characiformes: Prochilodontidae) no açude Marechal Dutra, Rio Grande do Norte, Brasil. Biota Amazônia, v. 2, p. 31-43, 2012 a.

54. NASCIMENTO, W.S., ARAÚJO, A.S., BARROS, N.H.C., GURGEL, L.L., COSTA, E.F.S., CHELLAPPA, S. Length-Weight relationship for seven freshwater fish species from Brazil. Journal of Applied Ichthyology, v. 28, p. 272-274, 2012b.

55. NASCIMENTO, M.M. Biologia reprodutiva do curimatã comum, Prochilodus brevis Steindachner, 1875 e limnologia do açude Marechal Dutra localizada na Caatinga do Rio Grande do Norte. Dissertação de Mestrado em Ciências Biológicas, Universidade Federal do Rio Grande do Norte, p.85, 2006.

56. NIKOLSKY, G.V. The ecology of fishes. London: Acad. Press, 1963.

57. NORMANDO, F.T., ARANTES, F.P., LUZ R.K. Repro- duction and fecundity of tucunaré, Cichla kelberi (perciformes: cichlidae), an exotic species in três marias reservoir, southeasternBrazil. Journal of Applied Ichthyology, v. 25, n. 3, p. 299-305, 2009.

58. NUNES, D.M., PELLANDA, M., HARTZ, S.M. Dinâmica reprodutiva de Oligosarcus jenynsii e Oligosarcus robustus (Characiformes, Characidae) na lagoa Fortaleza, Rio Grande do Sul, Brasil. Iheringia, Porto Alegre, vol. 94, no. 1, 5-11, 2004.

59. OLELE, N. F. Reproductive Biology of Sarotherodon galilaeus (Artedi, 1757) in Onah Lake, Delta State, Nigeria. Journal of Applied Sciences Research, v. 6, n. 12, p. 1981-1987, 2010.

60. PATIMAR R., MOHAMMADZADEH, B. On the biological characteristics of Capoeta fusca Nikolskii, 1897 in eastern Iran. Journal of Applied Ichthyology, v. 27, n. 3, p. 873- 878, 2011.

61. PESSOA, E.K.R., LIMA, L.T.B., CHELLAPPA, N.T., SOUZA, A.A., CHELLAPPA, S. Aspectos alimentares e reprodutivos do cascudo, Hypostomus pusarum (Starks, 1913) (Osteichthyes: Loricariidae) no açude Marechal Dutra, Rio Grande do Norte, Brasil. Biota Amazônia, v. 3, p. 45-53, 2013.

62. PRESTES, L., SOARES, M.G.M., SILVA, F.R., BITTENCOURT, M.M. Dinâmica populacional de Triportheus albus, $T$. angulatus e $T$. auritus (CHARACIFORMES: CHARACIDAE) em lagos da Amazônia Central. Biota Neotropica, v. 10, n. 3, 2010.

63. PARSONS, T.R., TAKAHASHI, M., HARGRAVE, B. Biological Oceanographic Processes. Pergamon Press: Oxford, 330p. 1984.

64. RODRIGUES, A.M., SANTOS, R.A., GIAMAS, M.T.D., CAMPOS, E.C., CÂMARA, J.J.C. Tipo de desova e fecundidade do lambari prata Astyanax schubarti Britski, 1964 (Pisces, Characiformes, Characidae), na represa de Ibitinga, Estado de São Paulo, Brasil. Boletim do Instituto de Pesca, v. 22, p. 133-139, 1995.

65. ROSA, R.S., MENEZES, N.A., BRITSKI, H.A., COSTA, W.J.E.M., GROTH, F. Diversidade, padrões de distribuição e conservação dos peixes da Caatinga. P. 135-180. In: LEAL, I. R.; TABARELLI, M.; SILVA, J. M. C. (Editores). Ecologia e Conservação da Caatinga. Recife: Editora da UFPE, p.822, 2005.

66. ROSA, R.S. Diversidade e conservação dos peixes da Caatinga. In: Silva, J.M.C., Tabarelli, M., Fonseca, M.T., Lins, L.V. orgs. Biodiversidade da Caatinga: áreas e ações prioritárias para a conservação. MMA, Brasília, DF, p.149-161, 2004.

67. SÁNCHEZ-BOTERO, J.I., REIS, V.S., CHAVES, D.N., GARCEZ, D.N. Fish assemblage of the Santo 
Anastácio reservoir (Ceará State, Brazil). Boletim do Instituto de Pesca, São Paulo, v. 40, p. 1 15, 2014.

68. SANTOS, S.L., VIANA, S.L.L.F., LIMA- JUNIOR, S.E. Fator de condição e desenvolvimento gonadal de Pimelodella cf. gracilis (Osteichthyes, Pimelodidae) no rio Amambaí - MS. 2005. Monografia (Graduação Ciências Biológicas) Universidade Estadual de Mato Grosso do Sul, Naviraí, 2005.

69. SATO, Y., SAMPAIO, E.V., FENERICH-VERANI, N., VERANI, J.R. Biologia reprodutiva e reprodução induzida de duas espécies de Characidae (Osteicthyes, Characiformes) da bacia do São Francisco, Minas Gerais, Brasil. Revista Brasileira de Zoologia,n. 23, v.1, p. 267-273,2006.

70. SATO, Y., FENERICH-VERANI, N., NUNER, A.P.O.N., GODINHO, H.P., VERANI, J.R. Padrões reprodutivos de peixes da bacia do São Francisco. In: GODINHO, H.P.; GODINHO, A.L. (Eds). Águas, peixes e pescadores do São Francisco das Minas Gerais. Belo Horizonte: PUC Minas. p. 229-274, 2003.

71. SILVA FILHO, J.J., NASCIMENTO, W.S., ARAUJO, A.S., BARROS, N.H.C., CHELLAPPA, S. Reprodução do peixe piau preto Leporinus piau (Fowler, 1941) e as variáveis ambientais do açude Marechal Dutra, Rio Grande do Norte. Biota Amazônia, v. 2, p. 10-21, 2012.

72. SOUZA, J.E., FRAGOSO-MOURA, E.N., FENERICH-VERANI, N., ROCHA, O., VERANI, J.R. Population structure and reproduc- tive biology of Cichla kelberi (Perciformes, Cichlidae) in Lobo Reservoir, Brazil. Neotropical Ichthyology, v. 6, n. 2, p. 201-210, 2008.

73. VAZOLLER, A.E.A.M. Biologia da Reprodução de Peixes Teleósteos: Teoria e Prática. Maringá, EDUEM. 169p. 1996.

74. VICENTINI, R.N., ARAÚJO, F.G. Sex ratio and size structure of Micropogonias furnieri (Desmarest, 1823) (Perciformes, Sciaenidae) in Sepetiba Bay. Brazilian Journal of Biology. v. 63, p. 559-566, 2003.

75. WEST, G. Methods of assessing ovarian development in fishes: a Review. Australian Journal of Marine \& Freshwater Research, v. 41, p. 199-222, 1990.

76. WINEMILLER, K.O., ROSE, K.A. Patterns of life-history diversification in North American fishes: implications for population regulation. Canadian Journal of Fisheries and Aquatic Sciences, v. 49, p. 2196-2218, 1992. 